\title{
Effect of a high fat diet on ovary morphology, in vitro development, in vitro fertilisation rate and oocyte quality in mice
}

\author{
Maryam Sohrabi ${ }^{1}$, PhD, Amaneh Mohammadi Roushandeh ${ }^{2}, \mathrm{PhD}$, Zohreh $\underline{\text { Alizadeh }}^{2}$, PhD, Aliasghar $\underline{\text { Vahidinia }}^{3}$, PhD,
} Mehrangiz Vahabian ${ }^{4}$, PhD, Mahnaz Hosseini $^{5}$, MSc

\begin{abstract}
INTRODUCTION The aim of this study was to determine the effect of a high-fat diet (HFD) on oocyte maturation and quality in a mouse model.

METHODS Female BALB/c mice were allocated to one of the following groups: (a) control group $(n=40)$, which received a controlled diet; or (b) HFD group $(n=40)$, which received an HFD for 12 weeks. Sections of the ovary were examined histologically. The number of follicles and corpora lutea were counted. In vitro maturation and in vitro fertilisation (IVF) were assessed in germinal vesicle (GV) and metaphase II (MII) oocytes, respectively. The expression of bone morphogenetic protein 15 (BMP15) and leptin receptor genes in GV and MII oocytes was evaluated using reverse transcription real-time polymerase chain reactions.

RESULTS In the HFD group, there was a decreased number of primordial and Graafian follicles, as well as corpora lutea $(p<0.05)$. The rate of oocyte development to the MII stage was also reduced $(p<0.001)$. Cumulus expansion was observed more frequently in the control group than the HFD group $(p<0.05)$. The IVF rate in the HFD group was lower than that in the control group $(p<0.05)$. In the HFD group, BMP15 and leptin receptor genes were upregulated in the GV stage $(p>0.05)$ and MII stage $(p<0.05)$, compared to the control group.

CONCLUSION An HFD reduces folliculogenesis in the primordial and Graafian stages, in vitro maturation and in vitro fertilisation rates, as well as oocyte quality in mice.
\end{abstract}

Keywords: BMP15, fertility, high-fat diet, leptin receptor, oocyte

\section{INTRODUCTION}

Obesity is a worldwide problem that affects public health. In 2008 , over 1.4 billion adults (i.e. persons aged $\geq 20$ years) in the world were overweight (body mass index [BMI] $>25 \mathrm{~kg} / \mathrm{m}^{2}$ ). ${ }^{(1)}$ According to Kelly et al, if this trend continues, $57.8 \%$ of the world's adults will be overweight or obese by 2030.(2) Based on statistics published by the World Health Organization in 2013, the incidence of obesity has doubled worldwide since $1980 .^{(1)}$

Women are at a higher risk of obesity and this risk may increase with age. ${ }^{(1,3,4)}$ While most obese women are not infertile, the negative impact of obesity on fecundity and fertility is well documented. Obese women have been shown to be three times more likely to suffer from infertility compared with women who have normal BMls. ${ }^{(5)}$ Another study showed that women with polycystic ovary syndrome and obesity have smaller oocytes than women in the control group; it also showed that when the women were further subdivided according to their BMI, both polycystic ovary syndrome and obesity were found to influence oocyte size, independent of one another. ${ }^{(6)}$ In a study conducted by Wittemer et al, a decrease in the number of collected oocytes was observed in long stimulation protocol cycles when the BMIs of the women were $\geq 25 \mathrm{~kg} / \mathrm{m}^{2}$. ${ }^{(7)}$

Defects in ovarian function that are associated with dietinduced obesity result in poor oocyte quality, reduced blastocyst survival rates and abnormal embryonic cellular differentiation. ${ }^{(8)}$ It has been shown that raised BMls contribute to worse outcomes for assisted reproductive techniques, including lower pregnancy and live birth rates, and a higher miscarriage rate. This could be due to the detrimental effect that elevated BMIs have on oocyte and embryo quality. ${ }^{(9)}$ A study, which examined the effect of obesity on pregnancy via intracytoplasmic sperm injection, found that pregnancy rates were significantly lower in women with a $\mathrm{BMI}>25 \mathrm{~kg} / \mathrm{m}^{2}$; these women also had higher duration of ovarian stimulation, gonadotropin requirements and spontaneous miscarriages as compared to women with a BMI $\leq 25 \mathrm{~kg} / \mathrm{m}^{2}$. Obesity could have been a risk factor for oocyte maturity, accounting for the increased doses of gonadotropin stimulation required by obese women. ${ }^{(10)}$ Jungheim et al demonstrated that apoptosis was specifically increased and oocytes were smaller in the preovulatory ovarian follicles of obese mice; reduction in oocyte maturity was also observed. ${ }^{(11)}$ In another study, Shah et al observed that obesity was associated with fewer normally fertilised oocytes, lower estradiol levels, and lower pregnancy and live birth rates. ${ }^{(12)}$ Infertile women who require in vitro fertilisation (IVF) should be encouraged to maintain a healthy weight during treatment. ${ }^{(12)}$

Leptin is a $16 \mathrm{kDa}$ small peptide that is secreted by adipose tissue. It is known to be associated with food consumption and the

\footnotetext{
${ }^{1}$ Research Center for Molecular Medicine, ${ }^{2}$ Endometrium and Endometriosis Research Center, ${ }^{3}$ Department of Nutrition, ${ }^{4}$ Department of English and Persian Literature, ${ }^{5}$ Anatomical Sciences Department, Hamadan University of Medical Sciences, Hamadan, Iran

Correspondence: Dr Mahnaz Hosseini, Lecturer, Anatomical Sciences Department, School of Medicine, Hamadan University of Medical Sciences, Shahid Fahmideh Street, 65178-3-8736, Hamadan, Iran. mhosseini1@yahoo.com
} 
regulation of body weight, similar to the role of insulin in type II diabetes mellitus. However, leptin, which is produced within the ovary, also plays a role in the pathways that control reproduction, such as folliculogenesis. ${ }^{(13)}$ Bone morphogenetic protein 15 (BMP15) is an extremely important oocyte-derived growth factor that is required for normal folliculogenesis and the female fertility of mammals. BMP15 is a member of the transforming growth factor beta (TGF- $\beta$ ) superfamily, and its mRNA and protein are found exclusively in the oocytes of most species. ${ }^{(14,15)}$

Obesity affects fertility in various ways (e.g. by impacting ovulation and the development of oocytes). ${ }^{(5)}$ It is generally accepted that a high-fat diet (HFD) can be used to generate a valid rodent model for obesity. In the present study, we examine the effect of HFD on in vitro maturation (IVM), IVF and the expression levels of leptin receptor and BMP15 genes, using a mouse model.

\section{METHODS}

In the present study, we used 80 three-week-old female BALB/c mice. The mice were placed in cages (five per cage) under standard conditions - 12 hours light, 12 hours dark, $60 \% \pm 5 \%$ humidity, $30^{\circ} \mathrm{C} \pm 2{ }^{\circ} \mathrm{C}$ temperature, with easy access to food and water - for one week. Thereafter, the mice were divided into two groups, the HFD group and the control group. For 12 weeks, the mice in the control group $(n=40)$ received normal labbased food, while the mice in the HFD group $(n=40)$ received an HFD consisting of $18.3 \%$ protein, $20.1 \%$ carbohydrate and $60.9 \%$ fat. ${ }^{(16,17)}$ The ingredients for every $100 \mathrm{~g}$ of HFD were milk fat (31.65 g), soya oil (3.22 g), casein (25.84 g), maltodextrine $(16.14 \mathrm{~g})$, sucrose $(8.9 \mathrm{~g})$, alpha $(\alpha)$-cellulose $(6.5 \mathrm{~g})$, potassium citrate $(2.1 \mathrm{~g})$, dicalcium phosphate $(1.7 \mathrm{~g}), \mathrm{L}$-cysteine $(0.37 \mathrm{~g})$, calcium carbonate $(0.7 \mathrm{~g})$, choline chloride $(0.24 \mathrm{~g})$, mixed vitamins (1.27 g) and mixed minerals (1.27 g), (16,17) making up the aforementioned percentages of protein, carbohydrate and fat. The energy received by each group of mice was measured by weighing the mice every two weeks.

At the end of 12 weeks, the mice in Group 1 (i.e. 20 mice from the HFD group and 20 mice from the control group) were superovulated with $10 \mathrm{IU}$ pregnant mare serum gonadotropin (PMSG). About 44-45 hours later, the mice were sacrificed by cervical dislocation. Germinal vesicle (GV) oocytes were obtained from the superovulated mice for IVM assessment. The mice in Group 2 (i.e. 20 mice from the HFD group and 20 mice from the control group) were given an injection of 10 IU PMSG for follicle development at the end of 12 weeks. A secondary injection of $10 \mathrm{IU}$ human chorionic gonadotropin (HCG) was administered 46 hours after the first injection. The mice were sacrificed 16 hours later and metaphase II (MII) oocytes were obtained from these mice.

Ovarian tissues were harvested from the sacrificed mice. The tissues were fixed in $10 \%$ neutral formalin and embedded in paraffin blocks. Sections measuring $5 \mu$ in thickness were obtained, deparaffinised and stained with haematoxylin and eosin. The sections were cut around the centre, along the long axis of the ovary. The number of ovarian follicles and corpora lutea in each section were counted. The follicles observed were classified into four groups: (a) primordial follicles - the oocyte is closely surrounded by a single layer of squamous granulosa cells; (b) primary follicles - the growing oocyte is surrounded by a single layer of cuboidal cells, or a multilayered mass of granulosa cells together with theca cells; (c) secondary (pre-antral) follicles - the oocyte is surrounded by several layers of granulosa cells together with theca cells and is adjacent to a single large antrum; and (d) Graafian (antral) follicles - the oocyte is surrounded by cumulus oophorus cells, and is adjacent to a single large antrum (Fig. 1).

The average number of follicles (including all four groups of follicles) and the average number of corpora lutea in five sections of the ovary ( $\mathrm{Cf}$ ) was counted according to the method described by Tanaka et al. ${ }^{(18)}$ The volume of the ovary (Vo) was calculated using half of the long axis (in $\mu \mathrm{m}$; a) and half of the short axis (in $\mu \mathrm{m}$; b) of the ovary. The volume of the section $(\mathrm{Vs})$ was calculated using the long and short axes, and the thickness of a section (i.e. $5 \mu \mathrm{m}$ ). The thickness of the ovary (in $\mu \mathrm{m}$; c) and the maximum diameter of the follicles (Df) in each section were measured. The number of follicles $(\mathrm{Nf})$ was determined using the following formulae:

$$
\begin{aligned}
& \mathrm{Nf}=\mathrm{Cf} \times \frac{V_{0}}{V_{s}} \times \frac{\mathrm{C}}{\mathrm{Df}} \\
& \mathrm{Vo}=\frac{4}{3} \pi \mathrm{ab}^{2} \\
& \mathrm{Vs}=\pi \mathrm{ab} \times 5 \\
& \mathrm{Nf}=\mathrm{Cf} \times \frac{\frac{4}{3} \pi \mathrm{ab} b^{2}}{\pi \mathrm{ab} \times 5} \times \frac{\mathrm{C}}{\mathrm{Df}} \\
& \mathrm{Nf}=\mathrm{Cf} \times \frac{\frac{4}{3} \mathrm{bc}}{5 \times \mathrm{Df}}
\end{aligned}
$$

The diameter of each counted follicle and corpus luteum was measured using the Motic Images Plus 2.0 software (Micro-Optic, Motic China Group Co Ltd, Xiamen, China). The total number of each type of follicle was calculated (based on the aforementioned formulae) and the results were expressed in percentages.

For IVM assessment, GV oocytes were obtained from the mice in Group 1, which were superovulated with 10 IU PMSG at the end of 12 weeks. Cumulus-oocyte complexes (COCs) were retrieved directly from the follicles under a stereomicroscope, using two 27-gauge needles. The IVM medium consisted of AlphaMinimum Essential Medium Eagle ( $\alpha$-MEM) supplemented with $5 \%$ fetal bovine serum (GIBCO, Invitrogen, Darmstadt, Germany). All the collected GV oocytes were placed in $50 \mu \mathrm{L}$ microdrops of $\alpha$-MEM supplemented with $5 \%$ fetal bovine serum and overlaid with embryo-tested light mineral oil (Sigma-Aldrich Co, Buchs, Switzerland) for 14-16 hours, in a humidified atmosphere of 5\% carbon dioxide at $37^{\circ} \mathrm{C}$. The oocytes were observed at regular intervals using an inverted microscope; morphological changes in the nucleus or extrusion of the first polar body were used as the criterion for nuclear maturation of the GV oocytes (i.e. MII oocytes) (Fig. 2). At the end of the culture period, cumulus expansion was assessed using Tao et al's subjective scoring 

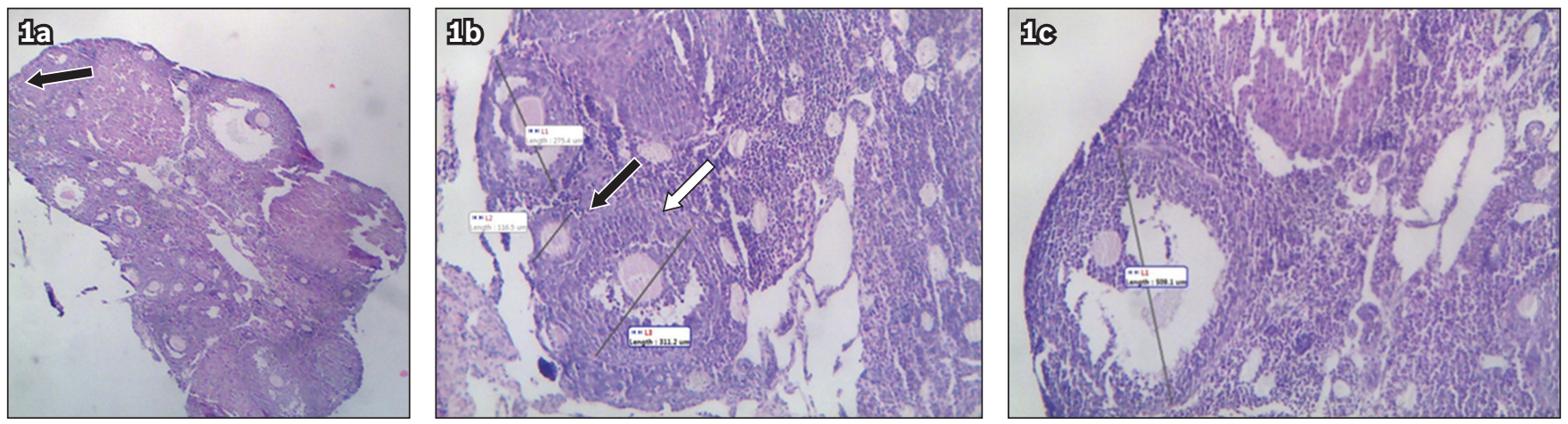

Fig. 1 Photomicrographs of ovarian follicles show (a) an ovary section, with a primordial follicle (arrow) (Haematoxylin \& eosin, $\times$ 4); (b) a primary follicle (white arrow) and a secondary follicle (black arrow) (Haematoxylin \& eosin, × 10); and (c) a Graafian follicle (Haematoxylin \& eosin, × 10).

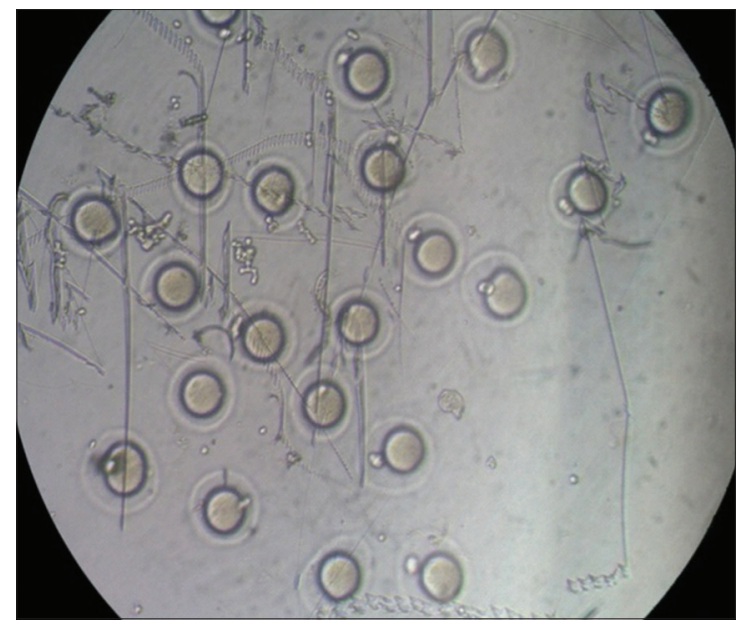

Fig. 2 Microscope photograph shows mouse germinal vesicle oocytes that have matured to the metaphase II stage.

method, ${ }^{(18)}$ with a few modifications. Cumulus expansions were classified into three classes: (a) good expansion - expansion of all layers of cumulus cells; (b) moderate expansion - expansion of the outer layers of cumulus cells; or (c) weak expansion - no response observed (Fig. 3).

MII oocytes were obtained from the fallopian tubes of the mice in Group 2 (Figs. 4a \& b) 16 hours after the secondary injection of 10 IU hCG and washed in IVF medium. For the IVF, sperm was collected from epididymal tail suspensions of eightweek-old male BALB/c mice. The sperm suspensions $(2 \times 106$ motile spermatozoa/mL) were capacitated for 2 hours in $1 \mathrm{~mL}$ of T6 media supplemented with $15 \mathrm{mg} / \mathrm{mL}$ bovine serum albumin. The in vitro matured oocytes of the mice from the HFD group and control group were placed into microdroplets $(50 \mu \mathrm{L})$ and the capacitated spermatozoa were added. After four hours of incubation, the MII oocytes were washed through with T6 medium. The MII oocytes were then cultured in a droplet of T6 medium (50 $\mu \mathrm{L}$ ) under mineral oil. After 24 hours, the oocytes were evaluated for cleavage of the two-cell zygote (Fig. 4c).

To check for gene expression, the GV and MII oocytes from both the HFD and control groups that underwent the IVM and IVF methods were gathered. The MII oocytes were denuded of their cumulus cells using hyaluronidase. A minimum of 20 oocytes were collected and placed in $300 \mu \mathrm{L}$ TRIzol and the collected oocytes were stored at $-80^{\circ} \mathrm{C}$ until use. To evaluate
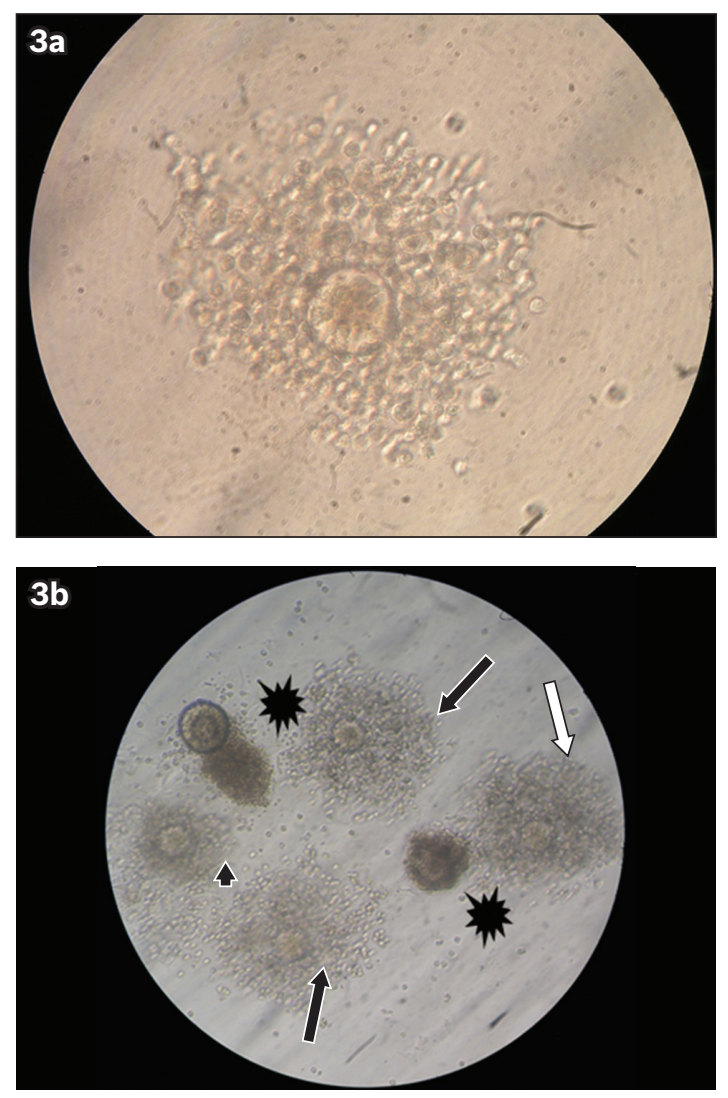

Fig. 3 Microscope photographs show (a) good cumulus expansion ( $\times 40$ ); and (b) good (black arrows), moderate (white arrow) and weak (arrowhead) cumulus expansions, and cumulus degeneration $\left({ }^{*}\right)(\times 10)$.

gene expression of BMP15, leptin receptor and glyceraldehyde 3-phosphate dehydrogenase (GAPDH; reference gene), total RNAs were extracted using the chloroform-isopropanol method. From the extracted RNA samples, $2 \mu \mathrm{L}$ was analysed using the Epoch Microplate Spectrophotometer (BioTek, Winooski, VT, USA).

Single-stranded cDNA was synthesised using an AccuPower RT PreMix Kit (Bioneer, Seoul, Korea) with $1 \mu$ g of RNA, according to the manufacturer's protocol. The process included incubation of the reaction mixture at $20^{\circ} \mathrm{C}$ for 30 seconds, followed by 5 minutes at $44^{\circ} \mathrm{C}, 30$ seconds at $55^{\circ} \mathrm{C}$ and 5 minutes at $95^{\circ} \mathrm{C}$. Quantitative real-time polymerase chain reaction (PCR) analyses were performed using the C1000 Thermocycler, CFX96 RealTime System (Bio-Rad, Hercules, CA, USA) and the QuantiFast SYBR Green PCR Kit (Qiagen, Seoul, Korea), in a final volume of 

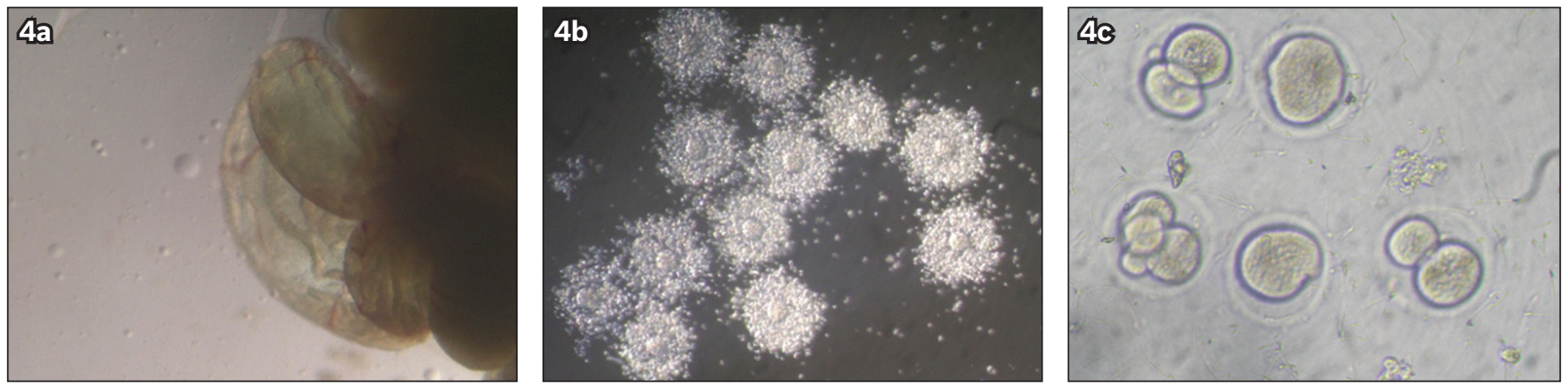

Fig. 4 Microscope photographs show (a) the part of a mouse fallopian tube that contains metaphase II (MII) oocytes; (b) cumulus-oocyte complexes containing MII oocytes; and (c) fertilised oocytes, some of which have developed to the two-cell zygote stage.

Table I. Characteristics of the primers used in real-time polymerase chain reaction.

\begin{tabular}{lllcc}
\hline Gene & $\begin{array}{l}\text { NCBI accession } \\
\text { number }\end{array}$ & Primer sequence & $\begin{array}{c}\text { Amplicon } \\
\text { length (bp) }\end{array}$ & $\begin{array}{c}\text { Annealing } \\
\text { temperature }\left({ }^{\circ} \mathbf{C}\right)\end{array}$ \\
\hline BMP15 & NM_009757.4 & $\begin{array}{l}\text { Forward: CAATGACACCGATGACAGAG } \\
\text { Reverse: GTATAGAGACGAGGAGCAATG }\end{array}$ & 242 & 47.3 \\
Leptin receptor & NM_010704.2 & $\begin{array}{l}\text { Forward: CAGTATTTATGGAAGGAGTTGG } \\
\text { Reverse: CAGTAGGACACAAGAGGAA }\end{array}$ & 131 & 61.2 \\
GAPDH & NM_008084.2 & $\begin{array}{l}\text { Forward: GGAGAAACCTGCCAAGTATGA } \\
\text { Reverse: GTCCTCAGTGTAGCCCAAGA }\end{array}$ & 91 & 60.1 \\
\hline
\end{tabular}

BMP15: Bone morphogenetic protein 15; GAPDH: glyceraldehyde 3-phosphate dehydrogenase

$25 \mu \mathrm{L}$ with $10 \mathrm{pmol}$ of each primer. The reaction was incubated at $95^{\circ} \mathrm{C}$ for 5 minutes, followed by 40 cycles of 15 seconds at $95^{\circ} \mathrm{C}, 30$ seconds at annealing temperature and 30 seconds at $72^{\circ} \mathrm{C}$. Fluorescence was then measured. Each assay was run in triplicate with each set of primers. Primer pairs for the amplification of cDNA coding for BMP15, leptin receptor and GAPDH were designed using information from the GenBank databases, and the AllelelD 6.0 software (Apticraft Systems Pvt Ltd, Madhya Pradesh, India) was used to check and ensure that there was minimum overlap. Information regarding the sequence of the primers, gene accession numbers, annealing temperature and product length is shown in Table I. The specificity of PCR amplifications was verified using a melting curve program $\left(70^{\circ} \mathrm{C}\right.$ to $95^{\circ} \mathrm{C}$ with a heating rate of $0.5^{\circ} \mathrm{C} / \mathrm{s}$ and continuous fluorescence measurement) and analysed by electrophoresis on a $1 \%$ agarose gel, $1 \times$ Tris-borate-ethylenediaminetetraacetic acid buffer.

Cycle threshold (Ct) values were obtained using the auto Ct function. Following efficiency correction, the mean value of Ct was calculated and then normalised to the reference gene $(\mathrm{GAPDH})$ using $\Delta \mathrm{Ct}$. Changes in relative expression were calculated using $2^{-\Delta \Delta c t}$. The specific transcripts were presented as a fold-change. Data was analysed using SPSS version 16.0 (SPSS Inc, Chicago, IL, USA). Data regarding animal weight and ovarian follicle count were examined using the $\chi^{2}$ test. IVF and IVM results were evaluated using binomial and $\chi^{2}$ tests. Gene expression data was analysed using the independent $t$-test. A p-value $\leq 0.05$ indicated statistical significance.

\section{RESULTS}

At the end of the 12 weeks, the mean weight gain of the mice from the HFD group was $4.65 \mathrm{~g} \pm 0.30 \mathrm{~g}$, while that of the mice from the control group was $5.49 \mathrm{~g} \pm 0.33 \mathrm{~g}$ (Table II). There was no
Table II. Mean body weight of the mice in the high-fat diet (HFD) and control groups.

\begin{tabular}{lrrr}
\hline Variable & \multicolumn{2}{c}{ Mean \pm standard deviation } & p-value* \\
\cline { 2 - 3 } & Control group & \multicolumn{1}{c}{ HFD group } & \\
\hline Initial weight $(\mathrm{g})$ & $18.57 \pm 0.26$ & $17.92 \pm 0.38$ & $<0.155$ \\
Final weight $(\mathrm{g})$ & $24.08 \pm 0.25$ & $22.57 \pm 0.29$ & $<0.001$ \\
Weight gain $(\mathrm{g})$ & $5.49 \pm 0.33$ & $4.65 \pm 0.30$ & $<0.065$ \\
\hline
\end{tabular}

*Data was analysed using $\chi^{2}$ test.

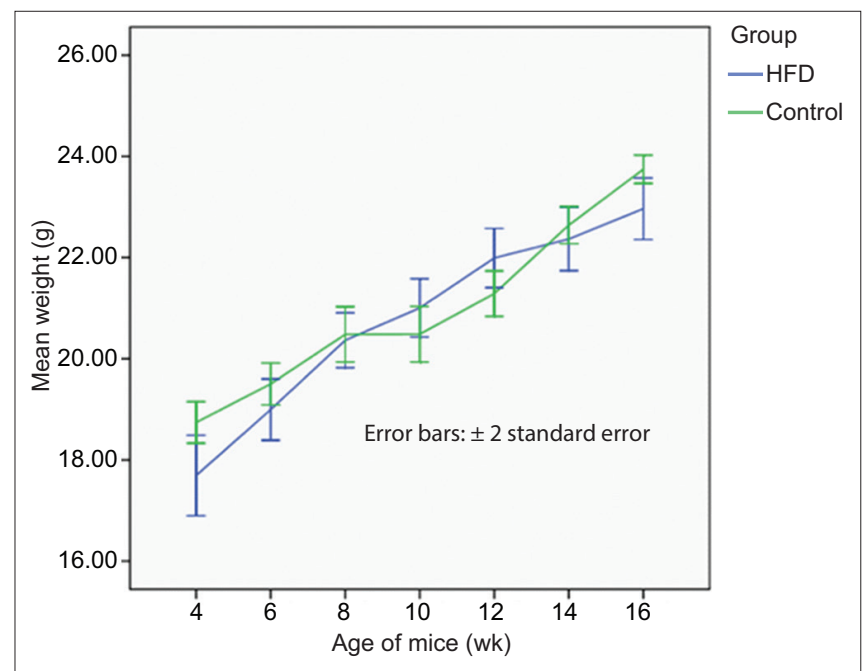

Fig. 5 Graph shows the changes in the mean body weights of the mice in the high-fat diet (HFD) and control groups over the 12 weeks.

significant difference between the groups in terms of the weight gained (Fig. 5).

The number of primordial and Graafian follicles from the mice in the HFD group was significantly lower than that from the mice in the control group $(p<0.001)$, while the number of 
primary and secondary follicles from the mice in the HFD group were significantly higher than that in the control group $(p=0.034)$ (Table III). The number of Graafian follicles found in the HFD group was half that of the mice in the control group $(p<0.001)$. The number of corpora lutea from the mice in the HFD group was 1.8 times less than that of the mice from the control group $(\mathrm{p}<0.001)$.

Table IV shows the number of oocytes that matured to the MII stage during IVM, as well as the number of degenerated and expanded COCs after culture for 24 hours. The maturation rate of GV oocytes in the HFD group was significantly lower than that of the control group $(p<0.01)$. The number of good expanded COCs in the HFD group was significantly higher than that of the control group $(p<0.05)$. However, the difference in the number of degenerated oocytes between the two groups was not significant $(p=0.212)$.

When the MII oocytes were analysed, we found that the number of MIl oocytes in the HFD group was significantly lower than that in the control group $(p<0.001)$ (Table V). While there was no significant difference between the two groups in the number of fertilised oocytes, there was a significant difference $(p<0.05)$ in the number of fertilised oocytes that developed to the two-cell zygote stage.

To evaluate the effect of HFD on BMP15 and leptin receptor gene expression in GV and MII oocytes, the mRNA of these oocytes was analysed using quantitative real-time PCR. When compared to the GV oocytes of the control group, the expression of BMP15 and leptin receptor genes was found to be upregulated in the GV oocytes of the HFD group ( $p>0.05$ ). BMP15 and leptin receptor levels were increased by $1.1-$ and 0.9 -fold, respectively, after normalisation with GAPDH. In the MII oocytes, the expression of the BMP15 and leptin receptor genes was higher in the HFD group than in the control group $(p<0.05)$; the expression levels of BMP15 and leptin receptor genes were increased by 15 - and 60 -fold, respectively. The PCR products of the BMP15 and leptin receptor genes are shown in Fig. 6.

\section{DISCUSSION}

Maternal obesity is well known to have a negative impact on fertility. The present study used a BALB/C mouse model to examine the impact of HFD on ovary morphology, IVM, IVF and oocyte quality. We found that the number of primordial and Graafian follicles decreased, while the number of primary and secondary follicles increased in the HFD group. This may be because the growth process of primordial follicles is independent of pituitary gonadotropins. There is evidence that the follicle cells in mice stimulate oocyte growth through paracrine factors. ${ }^{(19)}$ In addition, reciprocal regulation of granulosa cell growth by the oocyte probably occurs. ${ }^{(20)}$ In the present study, the number of Graafian follicles decreased in the HFD group. The mechanism for this decrease could be a direct effect on the hypothalamicpituitary axis. (21) The HFD induces complex changes in the regulation of the different components of the hypothalamuspituitary axis. ${ }^{(22)}$
Table III. Proportions of the follicles and corpora lutea found in the ovaries of the mice after 12 weeks.

\begin{tabular}{|c|c|c|c|}
\hline \multirow[t]{2}{*}{ Variable } & \multicolumn{2}{|c|}{$\%$} & \multirow[t]{2}{*}{ p-value* } \\
\hline & Control group & HFD group & \\
\hline Primordial follicle & 82.2 & 79.6 & $<0.001$ \\
\hline Primary follicle & 7.4 & 10.8 & $<0.001$ \\
\hline Secondary follicle & 6.9 & 7.2 & 0.034 \\
\hline Graafian follicle & 0.8 & 0.4 & $<0.001$ \\
\hline Corpus luteum & 2.8 & 1.9 & $<0.001$ \\
\hline
\end{tabular}

${ }^{*} \mathrm{p}$-value was analysed using $\chi^{2}$ test. HFD: high-fat diet

Table IV. Proportions of germinal vesicle (GV) oocytes that matured to the metaphase II (MII) stage, and cumulus-oocyte complex (COC) degeneration and expansion after 12 weeks.

\begin{tabular}{|c|c|c|c|}
\hline \multirow[t]{2}{*}{ Variable } & \multicolumn{2}{|l|}{$\%$} & \multirow[t]{2}{*}{ p-value } \\
\hline & Control group & HFD group & \\
\hline Total no. of GV oocytes* & 188 & 98 & $<0.001$ \\
\hline MII oocyte & 55.6 & 22.4 & $<0.001$ \\
\hline COC degeneration & 4.5 & 8.2 & 0.212 \\
\hline Good COC expansion & 63.3 & 74.5 & 0.056 \\
\hline Moderate COC expansion & 25.3 & 15.3 & 0.055 \\
\hline Weak COC expansion & 3.4 & 2.0 & 0.529 \\
\hline
\end{tabular}

*Data presented as no. TTotal number of GV oocytes was evaluated using binomial test. All other data was analysed using $\chi^{2}$ test. HFD: high-fat diet

Table V. The rates of in vitro fertilisation, and two-cell zygote development and degeneration after 12 weeks.

\begin{tabular}{lccc}
\hline Variable & \multicolumn{2}{c}{$\%$} & p-value $^{+}$ \\
\cline { 2 - 3 } & Control group HFD group & \\
\hline Total no. of MIl oocytes* & 219 & 99 & $<0.001$ \\
Two-cell zygote development & 75.8 & 27.3 & $<0.05$ \\
Two-cell zygote degeneration & 0.0 & 9.1 & $<0.05$ \\
No differentiation & 24.2 & 63.6 & $<0.05$ \\
\hline
\end{tabular}

* Data presented as no. TTotal number of metaphase II (MII) oocytes was evaluated using binomial test. All other data was analysed using $\chi^{2}$ test. HFD: high-fat diet

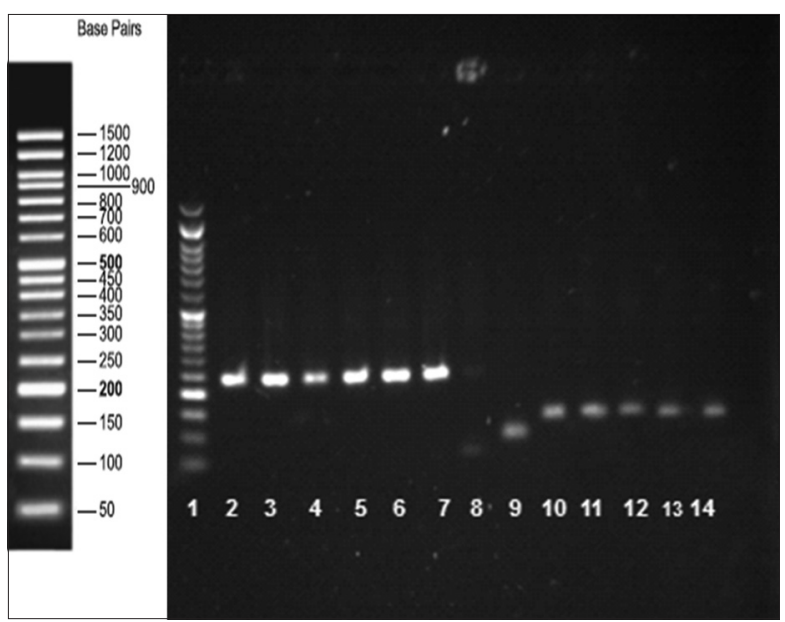

Fig. 6 Agarose gel electrophoresis of the real-time PCR products confirms the presence of the amplification products. Lane 1: DNA-ladder; lanes 2-7: BMP15 gene (242 bp); lane 8: negative control; lane 9: GAPDH (positive control, $91 \mathrm{bp}$ ); lanes 10-14: leptin receptor gene (131 bp). 
Cordier et al's study on an obese female rabbit model (induced by feeding rabbits an HFD [ $83 \%$ fat]) showed that, when compared to the control group, the rabbits in the HFD group had a higher number of atretic follicles and a lower number of antral follicles. ${ }^{(23)}$ In the present study, we showed that the maturation rate of the GV oocytes from the HFD group was significantly lower than that of the control group. It has been shown that an HFD could be associated with a rise in the level of reactive oxygen species in the COC, as well as glutathione depletion in preovulatory oocytes and zygotes of female mice. ${ }^{(24)}$ There was also a significant decrease in the number of MII oocytes in the HFD group in the present study. This finding is supported by similar studies that report decreased numbers of MII oocytes in mice with HFD-induced obesity. ${ }^{(25)}$

In the present study, the IVF results suggest that an HFD affects both the quality and quantity of the oocytes. Compared to the control group, the HFD group had a reduced number of MII oocytes collected from the fallopian tube and a reduced number of fertilised oocytes that differentiated to the two-cell zygote stage. There was also increased oocyte degeneration and an increased number of non-differentiated cells. All these observed changes negatively affect fertility.

Leptin is a protein hormone that is produced primarily by adipose tissue. The leptin receptor is a transmembrane receptor containing the glycoprotein 130 subunit; this subunit is also present in the interleukin 6 receptor and is found in many tissues, including those of the hypothalamus, lung, kidney and ovary. ${ }^{(26)}$ The results of the present study show that the expression of leptin receptor mRNA was increased in the GV and MII oocytes of the HFD group. This finding supports the study by Lange-Consiglio et al, which showed that the expression of leptin receptor mRNA and the rate of oocyte maturation may be related to obesity. ${ }^{(27)}$ Studies using real-time PCR have shown that leptin receptor mRNA is found in the human ovary. ${ }^{(28)}$ Mutations in the obese (ob) gene or the leptin receptor gene have been shown to result in obesity and infertility. ${ }^{(27)}$ Therefore, we can conclude that Leptin exerts direct effects on all ovarian cells and appears to have a physiological regulatory effect in folliculogenesis.

BMP15 is a well-known soluble growth factor that is derived from oocytes; it is important for normal cumulus cell function and hence normal oocyte development. ${ }^{(29)}$ The results of the present study show that the expression of BMP15 mRNA increased in the GV and MII oocytes of the HFD group. We also found that there was a higher number of cumulus expansions in the HFD group. These findings are supported by Su et al's study, which reported that cumulus expansion was impaired in BMP15 mutant mice. ${ }^{(29)}$

To conclude, based on the findings of the present study, the probable mechanisms of obesity-associated reproductive and developmental failure are an altered number of primodial and Graafian follicles, an altered number of corpora lutea, and an altered rate of GV oocyte development, IVF, cumulus expansion, BMP15 gene expression and leptin receptor gene expression.

\section{ACKNOWLEDGEMENTS}

The authors would like to express their gratitude to Elham Tohidnegad of the Department of Biostatistics and Epidemiology, Hamadan University of Medical Sciences, Hamadan, Iran, for her help in performing the statistical analysis in the present study.

\section{REFERENCES}

1. World Health Organization. Obesity and overweight: fact sheet no 311 [online]. Available at: http://www.who.int/mediacentre/factsheets/fs311/ en/. Accessed September 3, 2013.

2. Kelly T, Yang W, Chen CS, Reynolds K, He J. Global burden of obesity in 2005 and projections to 2030. Int J Obes (Lond) 2008; 32:1431-7.

3. Mirzazadeh A, Sadeghirad B, Haghdoost A, Bahreini F, Kermani MR. The prevalence of obesity in Iran in recent decade; a systematic review and meta-analysis study. Iranian J Public Health 2009; 38:1-11.

4. Popkin BM, Doak CM. The obesity epidemic is a worldwide phenomenon. Nutr Rev 1998; 56:106-14.

5. Brewer $\mathrm{CJ}$, Balen $\mathrm{AH}$. The adverse effects of obesity on conception and implantation. Reproduction 2010; 140:347-64.

6. Dokras A, Baredziak L, Blaine J, et al. Obstetric outcomes after in vitro fertilization in obese and morbidly obese women. Obstet Gynecol 2006; 108:61-9.

7. Wittemer C, OhI J, Bailly M, Bettahar-Lebugle K, Nisand I. Does body mass index of infertile women have an impact on IVF procedure and outcome? J Assist Reprod Genet 2000; 17:547-52.

8. Minge CE, Bennett BD, Norman RJ, Robker RL. Peroxisome proliferatoractivated receptor-gamma agonist rosiglitazone reverses the adverse effects of diet-induced obesity on oocyte quality. Endocrinology 2008; 149:2646-56.

9. Sobaleva S, El-Toukhy T. The impact of raised BMI on the outcome of assisted reproduction: current concepts. J Obstet Gynaecol 2011; 31:561-5.

10. Maheshwari A, Stofberg L, Bhattacharya S. Effect of overweight and obesity on assisted reproductive technology - a systematic review. Hum Reprod Update 2007; 13:433-44.

11. Jungheim ES, Schoeller EL, Marquard KL, et al. Diet-induced obesity model: abnormal oocytes and persistent growth abnormalities in the offspring. Endocrinology 2010; 151:4039-46.

12. Shah DK, Missmer SA, Berry KF, Racowsky C, Ginsburg ES. Effect of obesity on oocyte and embryo quality in women undergoing in vitro fertilization. Obstet Gynecol 2011; 118:63-70.

13. Joo JK, Joo BS, Kim SC, et al. Role of leptin in improvement of oocyte quality by regulation of ovarian angiogenesis. Anim Reprod Sci 2010; 119:329-34

14. Revelli A, Delle Piane L, Casano S, et al. Follicular fluid content and oocyte quality: from single biochemical markers to metabolomics. Reprod Biol Endocrinol 2009; 7:40.

15. Wu YT, Tang L, Cai J, et al. High bone morphogenetic protein-15 level in follicular fluid is associated with high quality oocyte and subsequent embryonic development. Hum Reprod 2007; 22:1526-31.

16. Furnes MW, Zhao CM, Chen D. Development of obesity is associated with increased calories per meal rather than per day. A study of high-fat diet-induced obesity in young rats. Obes Surg 2009; 19:1430-8.

17. Reeves PG, Nielsen FH, Fahey GC Jr. AIN-93 purified diets for laboratory rodents: final report of the American Institute of Nutrition ad hoc writing committee on the reformulation of the AIN-76A rodent diet. J Nutr 1993; 123:1939-51

18. Tao $\mathrm{Y}$, Xie $\mathrm{H}$, Hong $\mathrm{H}$, et al. Effects of nitric oxide synthase inhibitors on porcine oocyte meiotic maturation. Zygote 2005; 13:1-9.

19. Kidder GM, Vanderhyden BC. Bidirectional communication between oocytes and follicle cells: ensuring oocyte developmental competence. Can J Physiol Pharmacol 2010; 88:399-413.

20. Hussein TS, Thompson JG, Gilchrist RB. Oocyte-secreted factors enhance oocyte developmental competence. Dev Biol 2006; 296:514-21.

21. Baird DT, Campbell BK, Mann GE, McNeilly AS. Inhibin and oestradiol in the control of FSH secretion in the sheep. J Reprod Fertil Suppl 1991; 43:125-38.

22. Auvinen HE, Romijn JA, Biermasz NR, et al. The effects of high fat diet on the basal activity of the hypothalamus-pituitary-adrenal axis in mice. J Endocrinol 2012; 214:191-7.

23. Cordier AG, Léveillé $P$, Dupont $C$, et al. Dietary lipid and cholesterol induce ovarian dysfunction and abnormal $\mathrm{LH}$ response to stimulation in rabbits. PloS One 2013; 8:e63101. 
24. Igosheva N, Abramov AY, Poston L, et al. Maternal diet-induced obesity alters mitochondrial activity and redox status in mouse oocytes and zygotes. PloS One 2010; 5:e10074.

25. Ge ZJ, Luo SM, Lin F, et al. DNA methylation in oocytes and liver of female mice and their offspring: effects of high-fat-diet-induced obesity. Environ Health Perspect 2014; 122:159-64.

26. Ryan NK, Woodhouse CM, Van der Hoek KH, et al. Expression of leptin and its receptor in the murine ovary: possible role in the regulation of oocyte maturation. Biol Reprod 2002; 66:1548-54.

27. Lange-Consiglio A, Arrighi S, Fiandanese N, et al. Follicular fluid leptin concentrations and expression of leptin and leptin receptor in the equine ovary and in vitro-matured oocyte with reference to pubertal development and breeds. Reprod Fertil Dev 2013; 25:837-46

28. Löffler S, Aust G, Köhler U, Spanel-Borowski K. Evidence of leptin expression in normal and polycystic human ovaries. Mol Hum Reprod 2001; 7:1143-9.

29. Su YQ, Wu X, O'Brien MJ, et al. Synergistic roles of BMP15 and GDF9 in the development and function of the oocyte-cumulus cell complex in mice: genetic evidence for an oocyte-granulosa cell regulatory loop. Dev Biol 2004; 276:64-73. 